Research Article

\title{
Numerical Algorithms for Calculating Temperature, Layered Stress, and Critical Current of Overhead Conductors
}

\author{
Yongdou Liu, ${ }^{1,2}$ Zhiwei Chen ID, $^{2}$ and Quan Gu (iD) \\ ${ }^{1}$ Key Laboratory of Earthquake Engineering and Engineering Vibration, Institute of Engineering Mechanics, \\ China Earthquake Administration, Harbin 150080, China \\ ${ }^{2}$ Xiamen University School of Architecture and Civil Engineering, Xiamen 361005, China \\ Correspondence should be addressed to Quan Gu; quangu@xmu.edu.cn
}

Received 29 December 2019; Accepted 26 February 2020; Published 30 April 2020

Academic Editor: Arkadiusz Zak

Copyright (c) 2020 Yongdou Liu et al. This is an open access article distributed under the Creative Commons Attribution License, which permits unrestricted use, distribution, and reproduction in any medium, provided the original work is properly cited.

\begin{abstract}
Accurate calculation of temperature, stress, sag, and critical current (corresponding to critical temperature) of operational overhead conductors is important for ensuring the strength and sag safety of overhead lines. Based on 2D steady-state heat transfer equations, this article studies the temperature fields of the cross section of typical electrified conductors and establishes numerical simulation methods for calculating the layered stress, sag, and critical temperature. Using the algorithm, the relationship between the critical temperature and characteristics of conductors (e.g., the sag and tensile force) is studied. The results are verified by a comparison with the test results for heat-resistant aluminum alloy conductors JNRLH1/G1A-400/65 and JNRLH1/G1A-630/55. Finally, the paper studies the relationship between the critical temperature of the conductor and its most sensitive factors.
\end{abstract}

\section{Introduction}

During peak times, it is often necessary to dynamically increase the current of overhead lines to meet the power supply demands. In these cases, the stress and sag of conductors must be accurately calculated to avoid breakage due to excessive stress, multicircuit wire mixture [1], or nonenough safety distance to the ground caused by large sag. In addition, the stress at different layers of strands (called layered stress) and the sag are generally affected by the temperature fields on the conductor cross sections. Only when the temperature fields are simulated accurately can the layered stress and sag be calculated actually. Moreover, due to the uneven thermal expansion in different layers during operation, the mechanical properties of the conductor's cross section will greatly change at definite temperature which is defined as the critical temperature (CT) $[2,3]$. However, to the author's knowledge, there is limited research on the safety assessment of overhead conductors at the CT. Therefore, calculation of the temperature fields, layered stress, sag and tensile force, and the analysis of the safety of overhead lines at CT are of great significance.
Many experimental studies [4-12] have shown that the radial temperature of conductors is not evenly distributed. IEEE specifications [13] proposed that there is radial temperature gradient among each layer. In recent years, some methods [14-16] based on the finite element method were proposed to simulate the conductor radial temperature field. With these methods, models better conforming to the actual sectional structure of conductors can be established to avoid calculation errors due to improper values for effective thermal conductivity. However, these studies failed to fully consider the impact of cross-section gap distribution, interstrand contact, and convection conditions on the radial temperature field. Furthermore, there is little research that systematically studied the temperature field, layered stress, sag, and critical temperature of conductors. This paper proposes a complete set of numerical methods to calculate the temperature field, layered stress, and critical current (or temperature) of overhead conductors. The temperature field with voids is calculated by using the finite element method, and the layered stress and sag are calculated by using the temperature results. The CT and the corresponding critical current (CC) are calculated through the temperature and 
stress calculative method iteratively. By comparing the results of calculation with those of the experiments for a typical ACSR (aluminum-conductor steel reinforced), the algorithms are verified. In order to facilitate the dynamic assessment of safety of the conductors during the operation, this paper studies the relationship between the critical temperature of the conductor and its sensitive factors with the heat-resistant aluminum alloy conductor JNRLH1/G1A$400 / 65$ as an example.

\section{Calculation of Conductor Temperature Field}

The thermal balance equation of the entire cross section $\Omega$ of the conductor can be established [14]:

$$
k\left(T_{, x x}+T_{, y y}\right)+s=0, \quad(x, y) \in \Omega .
$$

And the boundary condition on the surface of the conductor $\Gamma$ can also be given [14]:

$$
q_{n}=-k\left(T_{, x} n_{x}+T_{, y} n_{y}\right)=\alpha\left(T-T_{a}\right), \quad l(x, y) \in \Gamma,
$$

where $T_{, x x}, T_{, y y}, T_{, x}$, and $T_{, y}$ indicate the second-order derivatives and first-order derivatives of the $2 \mathrm{D}$ temperature field $T$ in the conductor on the $x$ and $y$ coordinates, respectively; $q_{n}$ indicates the heat loss rate along the normal direction $n$ on the outer surface of the conductor; $n_{x}$ and $n_{y}$ are the components of $n$ in the direction of $x$ and $y ; \alpha$ indicates the composite heat loss coefficient; $T_{a}$ indicates the ambient temperature; $k$ is the thermal conductivity, represented by $k_{a}$ in the area of the aluminum strand, $k_{s}$ in the area of the steel core, and $k_{\text {air }}$ in the area of the air; and $s$ indicates the rate of heat per unit volume, represented by $s_{a}$ in the area of the aluminum strand, $s_{s}$ in the area of the steel core, and 0 in the area of the air. Herein, $k_{a}$ and $k_{s}$ are irrelevant to temperature field, while $k_{\text {air }}$ is relevant to it, and the relationship is as follows:

$$
k_{\mathrm{air}}=2.42 \times 10^{-2}+7.2 \times 10^{-5} T_{\mathrm{av}},
$$

where $T_{\mathrm{av}}$ indicates the average temperature of the cross section. The voltage of steel core per unit length is the same as that of aluminum strand. The current is inversely proportional to the resistance which is inversely proportional to the conductor cross section and proportional to the resistivity [14]. The ratio between the current $I_{s}$ of steel core and that $I_{a}$ of aluminum strand is

$$
\lambda=\frac{I_{s}}{I_{a}}=\frac{A_{s}}{A_{a}} \frac{\rho_{a}}{\rho_{s}},
$$

where $A_{s}$ and $\rho_{s}$ are the cross-sectional area and electrical resistivity of steel core, respectively, and $A_{a}$ and $\rho_{a}$ are the area and electrical resistivity of aluminum strand respectively. The rate of heat of steel core per unit volume $s_{s}$ is

$$
s_{s}=\frac{P \lambda /(\lambda+1)}{A_{s}} .
$$

External aluminum strands should consider solar energy [17], so the rate of heat per unit volume $s_{a}$ is

$$
s_{a}=\frac{P /(\lambda+1)}{A_{a}}+\frac{\gamma_{s} \mathrm{SD}}{A_{a}} .
$$

In equation (6), the first term on the right end of the equation is caused by the current, and the second term is caused by the solar radiation, $P$ indicates its total Joule heat gain [17] which is the function of the current, average temperature, and integrated resistance rate of the conductor, $S$ indicates the solar intensity, $\gamma_{s}$ indicates the solar absorption of the conductor with a value of $0.23-0.9$ and is usually valued at 0.5 , and $D$ indicates the conductor diameter.

An aluminum-conductor steel-reinforced cable (ACSR) mainly loses heat by means of convective cooling $P_{c}$ and radiative cooling $P_{r}$. The calculation of heat loss is provided in the literature [17]. According to the principle of constant heat loss per unit volume, the composite heat transfer coefficient of conductor surface in equation (2) can be determined:

$$
\alpha=\frac{P_{c}+P_{r}}{\left(T_{\text {sur }}-T_{a}\right) A},
$$

where $A$ indicates the lateral surface area of conductor per unit length (that is, the interface of the conductor and the external environment).

\section{Calculation of Conductor Stress Field}

This article assumes that conductors can only be resistant to tension, ignoring their resistance to shear, bend and torsion [18], and the tensile force on each strand of the same layer is equal [19]. Three basic conditions are required when performing calculations for overhead conductors: (1) deformation compatibility; (2) material constitutive relationship; and (3) balance of internal and external forces.

3.1. Deformation Compatibility. Using the condition of deformation compatibility, the strain of each strand can be represented by the longitudinal strain. For a strand with a length of $S_{i}$, if unfolding it, as shown in Figure 1, the deformation compatibility equation can be obtained as follows [20]:

$$
\varepsilon_{0} L_{s}=\frac{\Delta S_{i}}{\sin \alpha_{i}}+\frac{\Delta R_{i} \varphi_{i}}{\tan \alpha_{i}},
$$

where $\varepsilon_{0}$ indicates the axial strain of the overhead conductor; $L_{s}$ indicates the length of the overhead conductor corresponding to a strand with a length of $S_{i} ; \alpha_{i}$ indicates the angle between the tangent of layer $i$ of the strand and the conductor cross section; $\Delta R_{i} \varphi_{i}$ indicates the lateral deformation of the unfolded strand; and $\varphi_{i}$ indicates the ratio between projected length of the unfolded strand on the cross section and the outer radius $R_{i}$ of layer $i$ of the strand as follows:

$$
\varphi_{i}=S_{i} \cos \alpha_{i} / R_{i}
$$

From the geometrical relationship, equation (10) can be obtained as follows: 


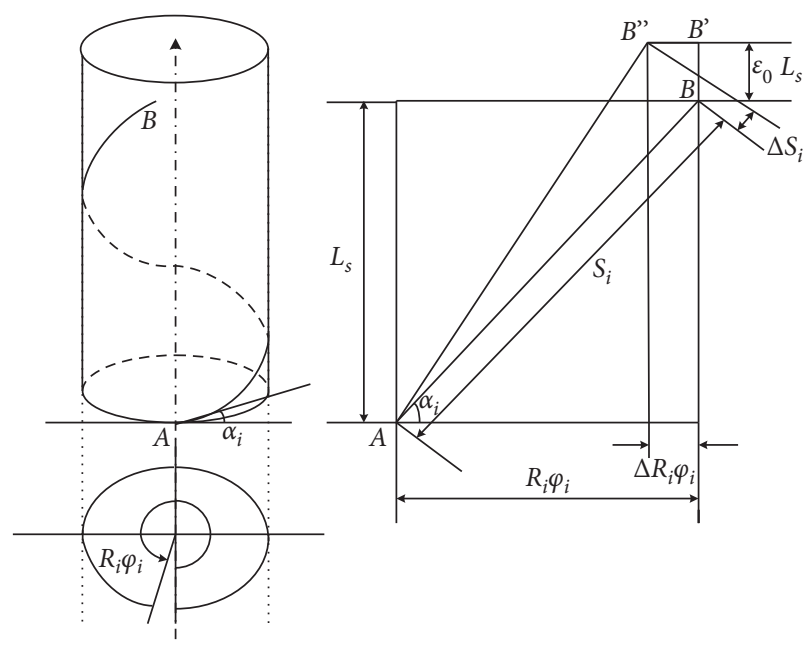

FIgURE 1: Unfolding view of the strand.

$$
\sin \alpha_{i}=\frac{L_{s}}{S_{i}} .
$$

Dividing the left and right sides of equation (8) by $S_{i}$ and simplifying it with equations (9) and (10), the relationship between the strain of layer $i$ of the strand and the conductor $\varepsilon_{0}$ is

$$
\varepsilon_{i}=\varepsilon_{0} \sin ^{2} \alpha_{i}-\frac{\Delta R_{i}}{R_{i}} \cos ^{2} \alpha_{i} .
$$

3.2. Lateral Deformation. From the inside to outside, the lateral deformation $\Delta R_{i}$ of conductors of layer $i$ includes three parts: (1) the deformation $\Delta r_{i 1}^{\prime}$ arising from crosssection shrinkage due to the Poisson effect when the strands of layer $i$ are stretched along their own axis [20]; (2) the deformation $\Delta r_{i 2}^{\prime}$ due to squeezing between layers; and (3) the deformation $\Delta r_{i T}^{\prime}$ due to thermal expansion (or contraction). Studies have shown that the lateral deformation $\Delta R_{i}$ has a nonlinear functional relation with axial strain $\varepsilon_{0}$. The calculation of $\varepsilon_{0}$ with $\Delta R_{i}$ requires iteration, which leads to complicated procedures. Furthermore, study on the lateral deformation of ACSR (JL/LB1A-300/50) found that the lateral deformation of the first two parts is very small (the lateral deformation of the first two parts is less than 1\%) [21] and can be neglected compared with that of the third part. The equation of lateral deformation can be simplified as follows:

$$
\Delta R_{i}=-\Delta r_{i T}^{\prime}
$$

The term $\Delta r_{i T}^{\prime}$ in equation (12) indicates the total deformation of layer $i$ due to changes in temperature.

$$
\Delta r_{i T}^{\prime}= \begin{cases}\Delta r_{1 T}, & i=1, \\ \Delta r_{1 T}+2 \sum_{j=2}^{i-1} \Delta r_{j T}+\Delta r_{i T}, & i=2, n .\end{cases}
$$

The equation of $\Delta r_{j T}$ (strand deformation due to thermal expansion or contraction) in equation (13) is as follows:

$$
\Delta r_{j T}=\alpha_{j T} r_{j}\left(T_{j}-20\right), \quad(j=1,2, \ldots n),
$$

where $\alpha_{j T}$ and $T_{j}$ indicate the coefficient of thermal expansion and the average temperature of $j^{\text {th }}$ layer, respectively. The strain $\varepsilon_{\mathrm{i} T}$ due to changes in temperature is as follows:

$$
\varepsilon_{i T}=\alpha_{i T}\left(T_{i}-20\right)
$$

3.3. Balance Equation of Internal and External Force. Linear elastic material is supposed in this article. The resultant axial internal force of the conductor section can be obtained by summing up all axial components of internal forces of strands on the cross section. The internal force of each strand of layer $i$ is as follows:

$$
p_{i}=E_{i}\left(\varepsilon_{i}-\varepsilon_{i T}\right) A_{i},
$$

where $E_{i}$ indicates the modulus of layer $i$ of the conductor; $A_{i}$ indicates the cross-sectional area of one strand in layer $i$. What needs to be mentioned is that the temperature strain $\varepsilon_{i T}$ (see equation (15)) of each layer of strands may differ due to the difference of the thermal expansion coefficient. As the temperature arises, aluminum strands with a higher thermal expansion coefficient may get zero stress, and even some of them get negative stress. As a result, all the external force is resisted by the steel strands. This may cause changes to the composite property of the overhead conductors and will be studied in detail in Section 4.2 later.

The equation of the axial internal forces on the cross section can be obtained as follows:

$$
P\left(\varepsilon_{0}\right)=\sum_{i=1}^{n} p_{i} n_{i} \sin \alpha_{i}
$$

where $n_{i}$ indicates the number of layer $i$ strands. Figure 2 is the diagrammatic sketch of single span overhead conductor, in which the letters " $A$ ", "B," and "O" represent the suspension points on the left and right and the lowest point, respectively. The span of the overhead conductor is $l$ and the height difference is $h$ (when suspension point B on the right is higher than A on the left, $h$ is positive, otherwise it is negative). The ratio between $h$ and $l$ is denoted as $\beta$. The axial tensile external force $N(x)$ at the distance $x$ from the left suspension point A (as shown in Figure 2) can be calculated according to the axial tensile stress at the lowest point $\mathrm{O} \sigma_{0}$ [18]. In equation (18), $\gamma$ denotes the gravity of conductor per unit length:

$$
N(x)=\sigma_{0} A_{0} \sqrt{1+\left[\tan \beta-\frac{\gamma(1-2 x)}{2 \sigma_{0} \cos \beta}\right]^{2}} .
$$

Thus, the force balance equation of the conductor section at distance of $x$ from the origin can be obtained as follows:

$$
f\left(\varepsilon_{0}\right)=N(x)-P\left(\varepsilon_{0}\right)=0 .
$$




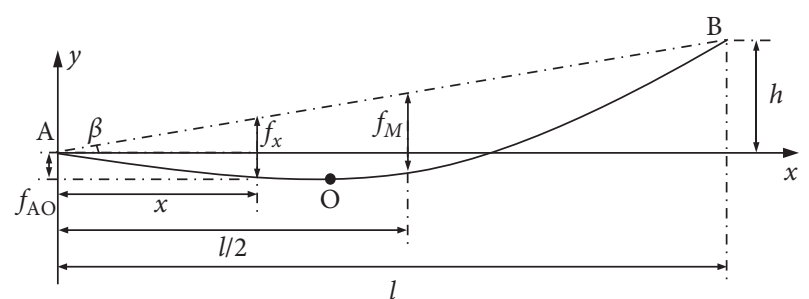

FIGURE 2: Diagrammatic sketch of the overhead conductors.

\section{Calculation of Sag and Critical Current (or Temperature)}

4.1. Sag. Sag refers to the vertical distance between the location of actual overhead lines and the line connecting the left and right suspension points, such as the sag $f_{M}$ at the midpoint of the conductor (shown in Figure 2). Studies showed that the sag of overhead conductors can be approximately represented by a parabola [18]. If suspension point A on the left is regarded as the origin, the sag $f_{x}$ at the location $x$ is as follows:

$$
f_{x}=f_{M} \cdot 4 x(l-x) / l^{2} .
$$

The relation between the sag $f_{M}$ in the midpoint of the conductor and its arc length $L$ is as follows [18]:

$$
f_{M}=\sqrt{\left(L-\frac{l}{\cos \beta}\right) \cdot \frac{3 l}{8 \cos ^{3} \beta}} .
$$

If the deformation (due to the gravity and other external loads) is neglected (that is, the axial rigidity of the conductor is assumed to be infinite), its initial arc length $L_{0}$ is as follows:

$$
L_{0}=\sqrt{\left(\frac{2 \sigma_{o}}{\gamma} \operatorname{sh} \frac{\gamma l}{2 \sigma_{o}}\right)^{2}+h^{2}}
$$

If the sag $f_{M}$ at the midpoint is known, the horizontal tensile stress can be calculated with the following equation:

$$
\sigma_{0}=\frac{\gamma l^{2}}{8 f_{M} \cos \beta} .
$$

If the sag $f_{M}$ at the midpoint is unknown but the height difference $f_{\text {AO }}$ between the left suspension point and the lowest point is known, the horizontal tensile stress can be obtained by solving the following equation:

$$
\frac{\sigma_{0}}{\gamma}\left[1-\operatorname{ch}\left(\frac{\gamma l}{2 \sigma_{0}}\right) \sqrt{1+\left(\frac{h}{L_{h=0}}\right)^{2}}\right]+\frac{h}{2}+f_{\mathrm{AO}}=0 .
$$

In the operation, the arc length of the overhead line will change with the effect of current and load. If the average strain of the whole overhead conductor is $\bar{\varepsilon}$, the arc length $L$ is

$$
L=L_{0}(1+\bar{\varepsilon})
$$

4.2. Critical Temperature and Critical Current. Overhead conductors are generally twisted by multilayers of strands. The deformation of each strand is caused by stress or due to changes in temperature. The deformation due to changes in temperature will not cause internal force in the strands. As the coefficients of thermal expansion and temperature of each layer of strands are different, their temperature deformations are also different. With the increase of temperature, the distribution of stresses in the strands of each layer will vary. If the resultant external force on the conductor is constant, when the temperature rises, the tensile stresses of strands with greater thermal deformation (aluminum strands with higher thermal expansion coefficients) will decrease while the stress of other strands (generally steel core with lower coefficients) will increase. When the temperature reaches a certain critical value, the resultant axial forces on all aluminum strands are zero. At this point, the average temperature of the cross section and the corresponding current are defined as critical temperature (CT) and critical current (CC), respectively. Note that the CT is the same concept as the knee-point temperature [22-24]. The CC $I_{\mathrm{c}}$ and CT $T_{\mathrm{c}}$ of the conductor meet the following conditions:

$$
\begin{aligned}
\left.P_{a}(I)\right|_{I=I_{c}} & =0, \\
P_{a}(I) & =\sum_{i=1}^{n_{a}} \sigma_{i}(I) m_{i} A_{i} \sin \alpha_{i}, \\
T_{c} & =T\left(I_{c}\right),
\end{aligned}
$$

where $P_{\mathrm{a}}(I)$ indicates the resultant force on the aluminum strands when the current is $I ; m_{i}$ indicates the number of aluminum strands of layer $I ; \alpha_{i}$ indicates the angle between the layer $i$ aluminum strands and the cross section; $A_{i}$ indicates the cross-sectional area of a single strand of the layer $i$ aluminum strand; $\sigma_{i}$ indicates the stress of layer $i$ aluminum strands; and $n_{\mathrm{a}}$ indicates the total layers of aluminum strands. CT and CC are related to span, height difference, external load (including its own weight), ambient temperature, wind speed, and solar heating.

4.3. Calculation Process. The CT, temperature field, sag, and layered stress proposed above can be calculated according to the flowcharts shown in Figure 3. The main calculative module indicates the process for calculating CT and CC. The submodules involve the calculation process of temperature field (submodule 1 in Figure 3 ) and the calculation process of sag and stress (submodule 2 in Figure 3 ). The two submodules need to be repeatedly called in the calculation of critical temperature. The calculation steps of the main module are as follows:

Step 1: set the initial values of current step size $d_{I}$, number of iterations $i=0$, and allowable error tol. Calculate the upper and lower limits of current. Perform steps 1.1-1.3: 


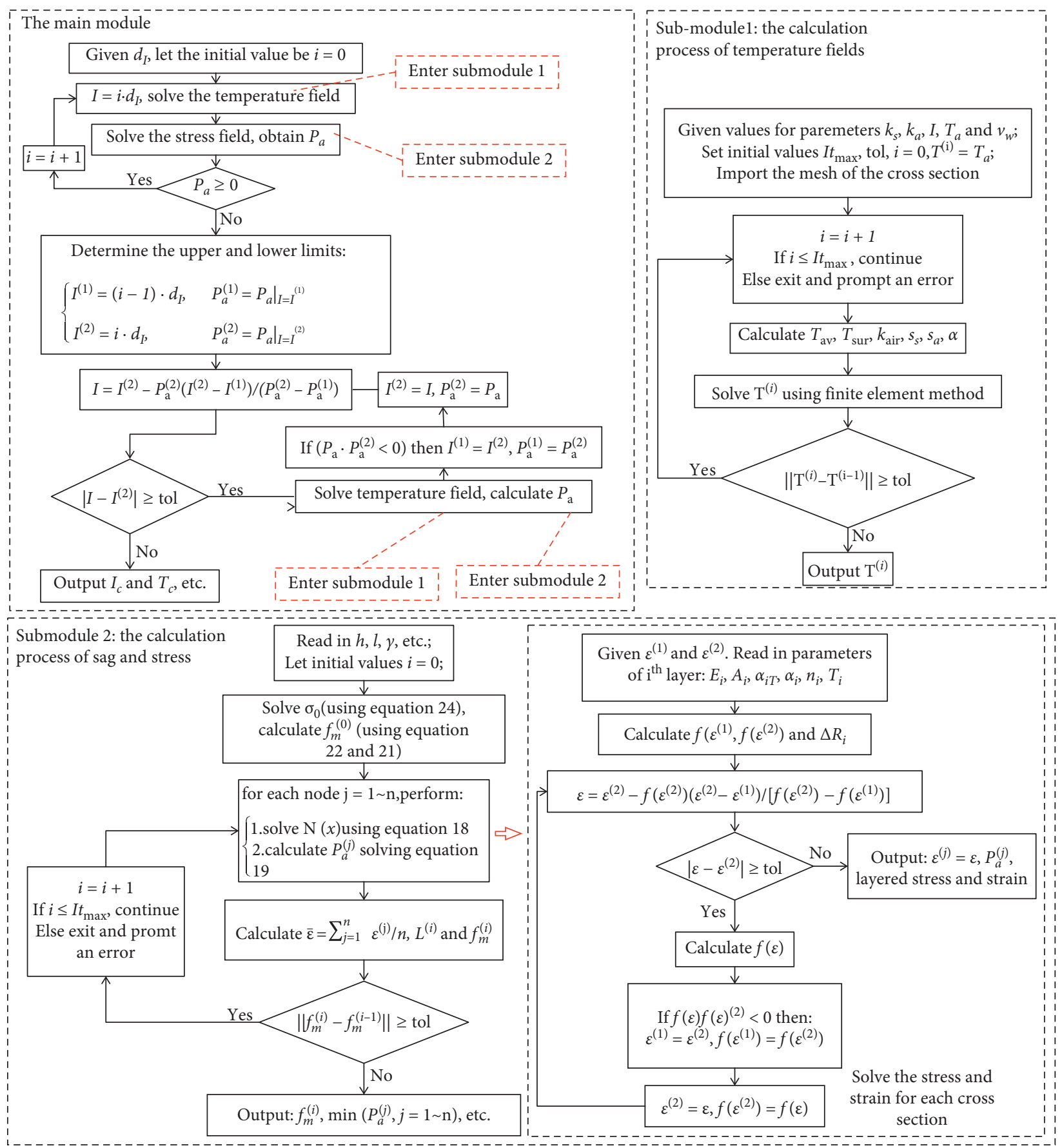

FIgURE 3: The calculation methods for critical temperature, temperature field, sag, and layered stress.

Step 1.1: call the submodule 1 to calculate the temperature field of the conductor cross section with a given current $I=i \cdot d_{I}$.

Step 1.2: call the submodule 2 to calculate the layered stress of the conductor and the resultant force $P_{\mathrm{a}}$ on aluminum strands (see equation (27)).

Step 1.3: if $P_{\mathrm{a}} \geq 0, i=i+1$, go to Step 1.1. Otherwise, the upper and lower limits of $\mathrm{CCI}^{(2)}=i \cdot d_{I}$ and $I^{(1)}=(i-1) \cdot d_{I}$ and the corresponding resultant force $P_{\mathrm{a}}^{(2)}$ and $P_{\mathrm{a}}^{(1)}$ on the aluminum strands are obtained.
Step 2: calculate the CT and CC with the false position method. Perform steps 2.1 2.3:

Step 2.1: update the CC $I=I^{(2)}-P_{\mathrm{a}}^{(2)}\left(I^{(2)}-I^{(1)}\right) /$ $\left(P_{\mathrm{a}}^{(2)}-P_{\mathrm{a}}^{(1)}\right)$ according to its upper and lower limits.

Step 2.2: if $\left|I-I^{(2)}\right| \geq$ tol, perform step 2.2.1 step 2.2.3:

Step 2.2.1: call the submodules 1 and 2 to calculate the resultant force $P_{\mathrm{a}}$ on the aluminum strands when the current is $I$.

Step 2.2.2: if $P_{\mathrm{a}} \cdot P_{\mathrm{a}}^{(2)}<0$, update the lower limit, i.e., $I^{(1)}=I^{(2)}, P_{\mathrm{a}}^{(1)}=P_{\mathrm{a}}^{(2)}$. 
Step 2.2.3: update the upper limit, i.e., $I^{(2)}=I, P_{\mathrm{a}}^{(2)}=P_{\mathrm{a}}$, and go to step 2.1.

Step 2.3: otherwise, output the critical current $I_{c}$, critical temperature $T_{c}$, and corresponding layered stress.

The calculation of temperature field is performed with fixed point iteration, and the calculative process is as follows:

Step 1: set the initial values of allowed maximum number of iterations $I t_{\max }$, allowed error tol, coefficient of thermal conductivity $k_{s}$ for steel core and $k_{a}$ for aluminum strands, current $I$, ambient temperature $T_{c}$, and wind speed $v_{\mathrm{w}}$, respectively. Import the crosssectional finite element mesh.

Step 2: update the number of iterations $i=i+1$. If $i \leq I t_{\max }$, continue; otherwise, the calculation fails; exit and prompt an error.

Step 3: calculate the average temperature $T_{\mathrm{av}}$ of the conductor cross section and the average temperature $T_{\text {sur }}$ of the conductor surface. Calculate $k_{\text {air }}, s_{s}, s_{a}$, and $\alpha$ with equations (3)-(7).

Step 4: solve the temperature field of the conductor cross section by using the finite element program derived from equations (1) and (2).

Step 5: if the temperature field $\mathbf{T}^{(i)}$ of the iteration is very different from the result $\mathbf{T}^{(i-1)}$ of the previous iteration (i.e., $\left\|\mathbf{T}^{(i)}-\mathbf{T}^{(i-1)}\right\| \geq$ tol), perform step 2-5.

Step 6: otherwise, converge the calculation and save the results.

The iterative process for calculating the sag and stress is as follows:

Step 1: import the geometric information of weight per unit length $\gamma, \operatorname{span} l$, height difference $h$, and initial sag $f_{\mathrm{AO}}$. Set the initial value of the iteration number $i=0$ and the maximum number of iterations $I t_{\text {max }}$.

Step 2: solve equation (24) to obtain the initial value of horizontal tensile stress $\sigma_{0}$. Calculate the initial iterative values $f_{m}^{(0)}$ of sag at the midpoint according to equations (22) and (21), respectively.

Step 3: equally divide the whole span of conductors into $n-1$ sections (totally $n$ nodes). For each node $j \in[1, n]$, calculate the strain and layered stress and the resultant force $P_{a}^{(j)}$ of aluminum strands. Perform the following steps:

Step 3.1: calculate the resultant external force $N(x)$ at the node $j$ of $x$ with equation (18).

Step 3.2: perform step 3.2.1 step 3.2.4 (false position method) to solve equation (19).

Step 3.2.1: given the upper and lower limits of the axial strain $\varepsilon^{(1)}$ and $\varepsilon^{(2)}$, read in the cross-sectional parameters of $i$ th layer including $E_{i}$ (see equation (16)), $A_{i}$ (in equation (16)), $\alpha_{i T}$ (in equation (15)), $\alpha_{i}$ (in equation (8)), $n_{i}$ (in equation (17)), and $T_{i}$ (in equation (14)).

Step 3.2.2: calculate the lateral deformation $\Delta R_{i}$ of each layer with equations (12)-(14). Calculate $f\left(\varepsilon^{(1)}\right)$ and $f\left(\varepsilon^{(2)}\right)$ combined with equations (11) and (15)-(19).

Step 3.2.3: update the axial strain $\varepsilon=\varepsilon^{(2)}-f\left(\varepsilon^{(2)}\right)\left(\varepsilon^{(2)}-\varepsilon^{(1)}\right) /\left[f\left(\varepsilon^{(2)}\right)-f\left(\varepsilon^{(1)}\right)\right]$ according to the upper and lower limits of axial strain.

Step 3.2.4: if $\left|\varepsilon-\varepsilon^{(2)}\right| \geq$ tol, perform steps 3.2.4.1 3.2.4.3:

Step 3.2.4.1: calculate $f(\varepsilon)$ combined with equations (11) and (15)-(19).

Step 3.2.4.2: if $f(\varepsilon) f\left(\varepsilon^{(2)}\right)<0$, update the lower limit of strain: $\varepsilon^{(1)}=\varepsilon^{(2)}, f\left(\varepsilon^{(1)}\right)=f\left(\varepsilon^{(2)}\right)$.

Step 3.2.4.3: update the upper limit of strain: $\varepsilon^{(2)}=\varepsilon, f\left(\varepsilon^{(2)}\right)=f(\varepsilon)$, go to step 3.2.2.

Step 3.2.5: otherwise (i.e., $\left|\varepsilon-\varepsilon^{(2)}\right|<$ tol), output the axial strain $\varepsilon^{(j)}=\varepsilon$, resultant force $P_{a}^{(j)}$ on aluminum strands, and layered stress and strain.

Step 4: calculate the average $\bar{\varepsilon}=\sum_{j=1}^{n} \varepsilon^{(j)} / n$ of strain at $n$ nodes. Calculate the arc length $L^{(i)}$ and sag $f_{m}^{(i)}$ at iteration $i$ with equations (25) and (21)

Step 5: if the sag $f_{m}^{(i)}$ at the midpoint in the iteration is very different from the result $f_{m}^{(i-1)}$ of the previous iteration (i.e., $\left\|f_{m}^{(i)}-f_{m}^{(i-1)}\right\| \geq$ tol), execute the steps 5.1-5.3:

Step 5.1: update the iteration number $i=i+1$.

Step 5.2: if the iteration number $i \leq I t_{\max }$ go to step 3 .

Step 5.3: else the calculation fails, exit and prompt an error.

Step 6: otherwise, (i.e., $\left\|f_{m}^{(i)}-f_{m}^{(i-1)}\right\|<$ tol), output the sag $f_{m}^{(i)}$ at the midpoint, the resultant force $\min \left(P_{a}^{(j)}, j=1 \sim n\right)$ on the aluminum strands at the lowest point in the span, etc.

\section{Comparison of Experimental and Numerical Results}

This section provides comparative analyses of the results from experiments and numerical simulation, including those for (1) cross-section temperature of ACSR JL/G1A630/55 [25]; (2) layered stress of ACSR JL/G1A-400/35; and (3) temperature-sag and temperature-tensile force characteristics of heat-resistant aluminum alloy strands JNRLH1/ G1A-400/65 and JNRLH1/G1A-630/55 with a span of $60 \mathrm{~m}$.

5.1. Layered Temperature. With reference to the experimental study [26] of conductor JL/G1A-630/55 in the different current and wind speed conditions, this article conducts numerical simulation of the conductor and sets up a finite element model, as shown in Figure 4. The model is performed with meshing by using triangular elements with a maximum size of $2.4 \mathrm{~mm}$ and with 8080 elements and 4184 finite element nodes. The results of numerical simulation and experiments are compared in Table 1. In the measurement of the conductor's temperature, the surface temperature of the conductors is recorded. However, in the numerical simulation, the temperature field on the whole 


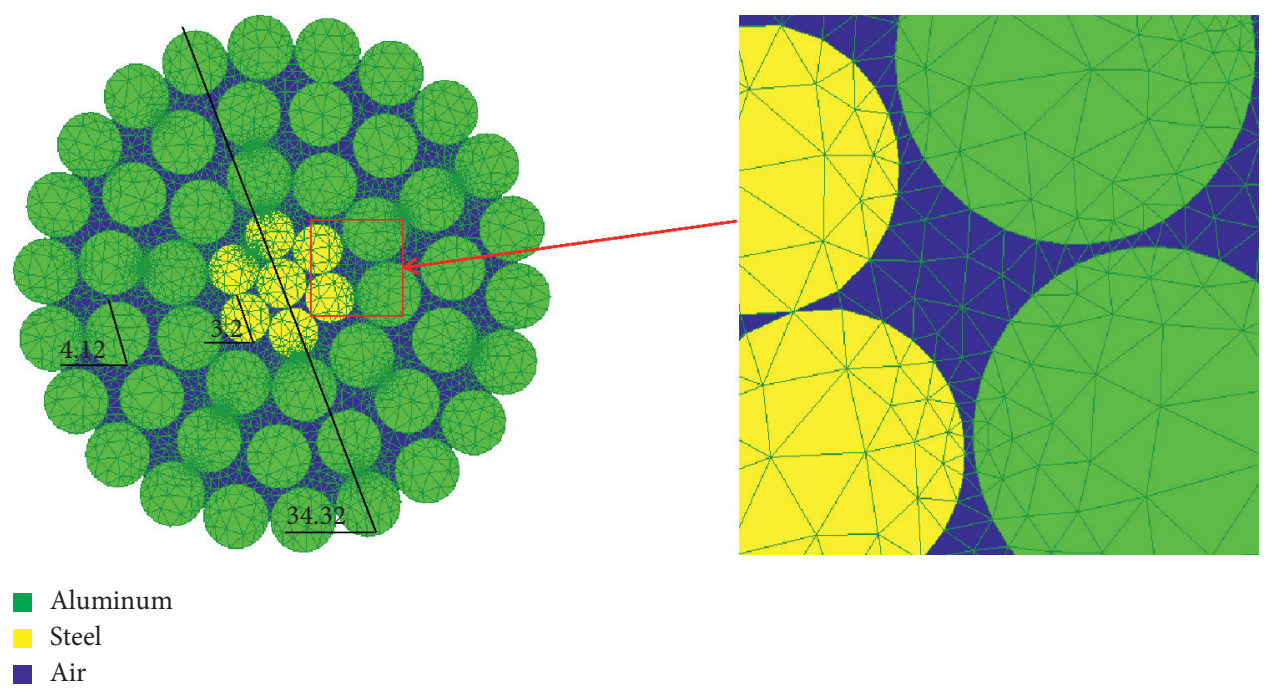

Figure 4: The finite element mesh of ACSR JL/G1A-630/55/mm.

TABLE 1: The experimental and numerical results of ACSR JL/G1A-630/55.

\begin{tabular}{|c|c|c|c|c|c|c|}
\hline \multirow{2}{*}{$\begin{array}{l}\text { Wind } \\
\text { speed }(\mathrm{m} / \mathrm{s})\end{array}$} & \multirow[b]{2}{*}{ Current (A) } & \multirow{2}{*}{$\begin{array}{c}\text { Ambient } \\
\text { temperature }\left({ }^{\circ} \mathrm{C}\right)\end{array}$} & \multirow{2}{*}{$\begin{array}{c}\text { Experimental value }\left({ }^{\circ} \mathrm{C}\right) \\
\text { Surface temperature }\end{array}$} & \multicolumn{3}{|c|}{ Numerical result $\left({ }^{\circ} \mathrm{C}\right)$} \\
\hline & & & & $\begin{array}{l}\text { Steel } \\
\text { core }\end{array}$ & $\begin{array}{l}\text { Aluminum strand } \\
\text { of inner layer }\end{array}$ & $\begin{array}{l}\text { Aluminum strand } \\
\text { of outer layer }\end{array}$ \\
\hline \multirow{3}{*}{0} & 922 & & 70 & 68.34 & 68.34 & 68.01 \\
\hline & 1106 & 31 & 84 & 82.87 & 82.86 & 82.38 \\
\hline & 1290 & & 98 & 100.16 & 100.15 & 99.48 \\
\hline \multirow{3}{*}{1} & 922 & & 42 & 46.90 & 46.90 & 46.62 \\
\hline & 1106 & 33.5 & 54 & 53.97 & 53.96 & 53.56 \\
\hline & 1290 & & 61 & 62.73 & 62.72 & 62.15 \\
\hline \multirow{3}{*}{2} & 922 & & 41 & 41.50 & 41.50 & 41.25 \\
\hline & 1106 & 33.5 & 45 & 45.97 & 45.96 & 45.60 \\
\hline & 1290 & & 51 & 51.48 & 51.47 & 50.97 \\
\hline \multirow{3}{*}{4} & 922 & & 38 & 37.56 & 37.55 & 37.33 \\
\hline & 1106 & 33 & 40 & 40.11 & 40.11 & 39.80 \\
\hline & 1290 & & 45 & 43.22 & 43.21 & 42.78 \\
\hline
\end{tabular}

cross section of the conductor can be calculated and then the average temperature of strands of each layer can be obtained.

Table 1 and Figure 5 show that (1) the surface temperature simulation results of the conductor at each wind speed fit well with the experimental values apart from individual data when the wind speed is $1 \mathrm{~m} / \mathrm{s}$ and the current is $922 \mathrm{~A}$. The simulation results are different from the experimental ones by $9.91 \%$ and the experimental data at this point are obviously unreasonable. Under the currents of $1106 \mathrm{~A}$ and $1290 \mathrm{~A}$, when the wind speed increases from $1 \mathrm{~m} / \mathrm{s}$ to $2 \mathrm{~m} / \mathrm{s}$, the surface temperature decreases by $9^{\circ} \mathrm{C}$ and $10^{\circ} \mathrm{C}$, respectively, compared to a $1^{\circ} \mathrm{C}$ reduction when the current is $922 \mathrm{~A}$. Therefore, the experimental value when the wind speed is $1 \mathrm{~m} / \mathrm{s}$ and the current is $922 \mathrm{~A}$ is lower than expected. (2) The difference of the cross-sectional temperature is small (about $1^{\circ} \mathrm{C}$ ) and the temperature of the internal strands is slightly higher than that of external strands. Therefore, the temperature gradients can be ignored in the calculation of layered stress. (3) With the increase of current, the cross-section temperature of the conductor rises, while with the increase of wind speed it drops.

5.2. Layered Stress. The layered stress experiment on JL/ G1A-400/35 ACSRs is performed through stripping, that is, stretching the conductor to a certain strain and successively stripping the conductors by layer to calculate the difference of axial force, so the layered stress of the conductor can be calculated under the strain. Only the layered stresses of the aluminum strands are studied, as the axial force is mainly resisted by the aluminum strands (more than 3 times than steel core). The experiment is performed at temperature $20^{\circ} \mathrm{C}$ without applying current.

The calculation and test results are compared in Figure 6, where the legend layer 1,2 , and 3 represent the external, middle, and internal layers of aluminum strands respectively. As shown in the figure: (1) the numerical simulation results in the elastic phase (with strain of less than $0.2 \%$ ) and 


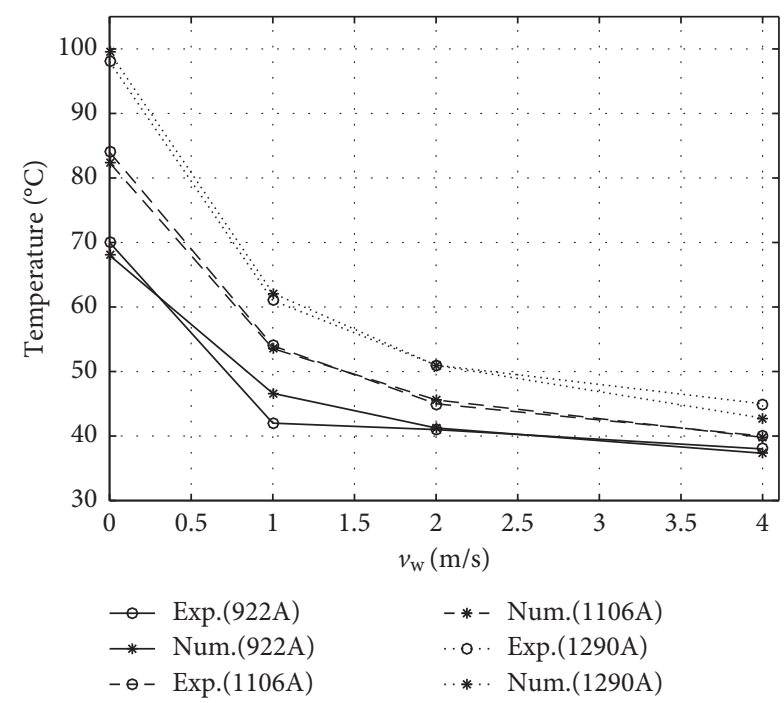

FIGURE 5: The experimental and numerical results of ACSR JL/ G1A-630/55.

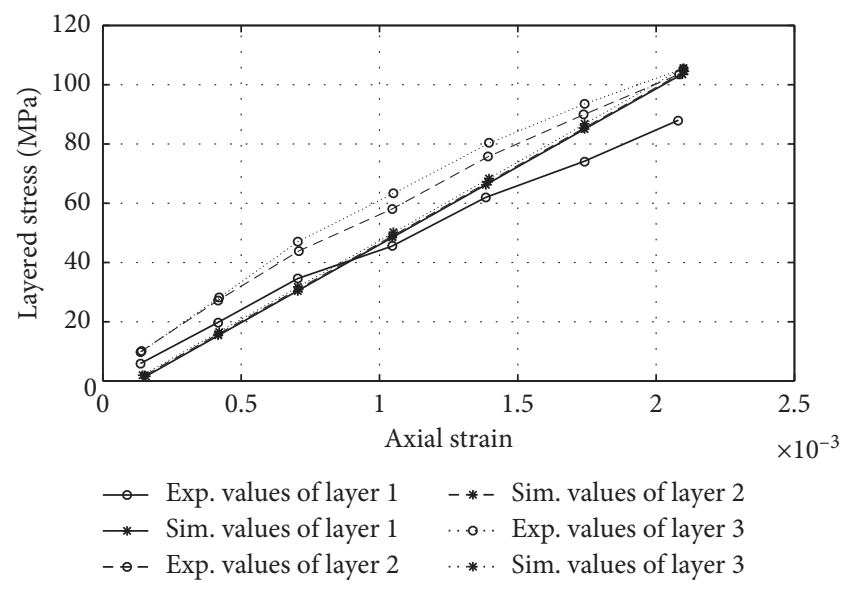

FIGURE 6: The comparison of layered stress-strain relationship of ACSR JL/G1A-400/35.

the experimental and numerical results agree each other with an acceptable accuracy; (2) the tensile stresses of the internal aluminum strands are slightly greater than external ones. There are still some differences between the two results (with maximum error of $17.6 \%$ ) which may be because the displacement deformation of strands under tension is random as strands of each layer cannot be closely arranged without any gap in the ACSR construction. It should be noted that although layered stress does not perform well, the resultant tensile stresses fit well with the experimental results, which will be discussed later.

5.3. Temperature-Sag Characteristics. The sag-temperature curves of heat-resistant aluminum alloy conductor JNRLH1/ G1A-400/65 (with initial tension of $38.8 \mathrm{kN}$ ) and JNRLH1/ G1A-630/55 (with initial tension of $48.5 \mathrm{kN}$ ) are compared in Figures 7 and 8. The curves reflect the change law of sag (at the midpoint) with the cross-sectional temperature. The

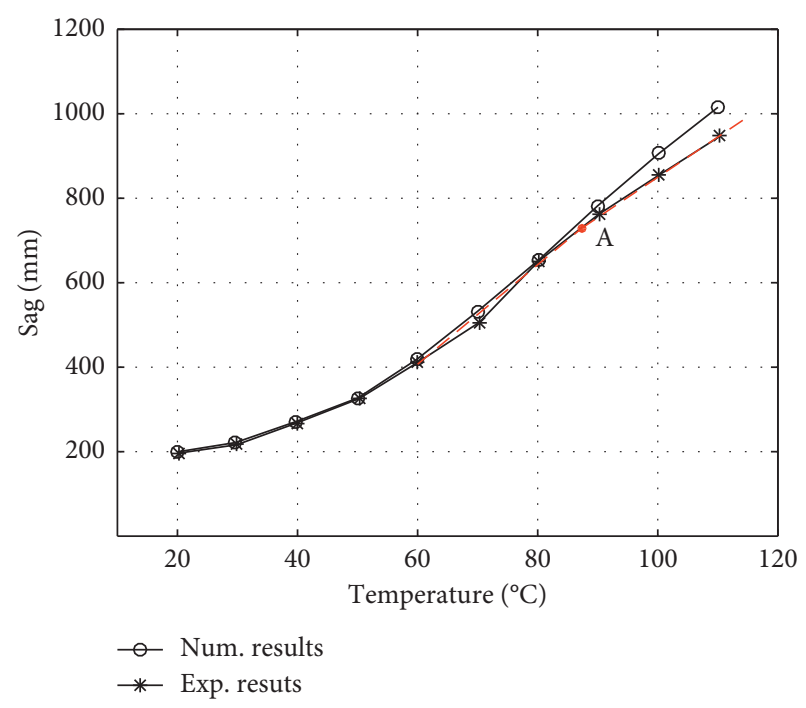

FIgURE 7: The temperature and sag characteristics of conductor JNRLH1/G1A-400/65.

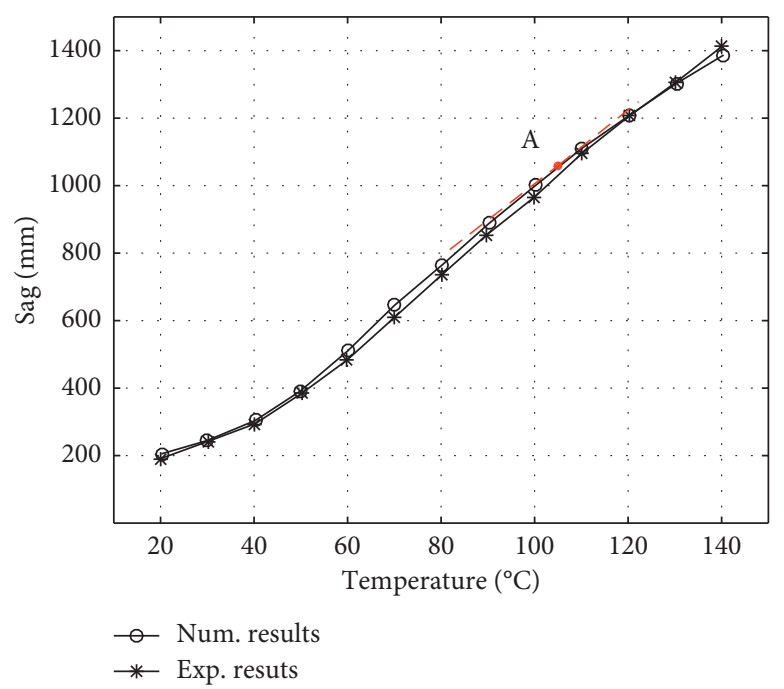

FIgURE 8: The temperature and sag characteristics of conductor JNRLH1/G1A-630/55.

experiment is performed as follows: fix the overhead lines (with a height difference of 0 ) on the equipment with a span of $60 \mathrm{~m}$. Then, gradually increase the temperature of the conductors by charging with electricity and measure the sag at the midpoint.

Figures 7 and 8 show that the numerical and experimental results of the two examples fit well (the maximum difference is $7.37 \%$ and $4.49 \%$, respectively). With the increase of temperature, the sag increases with a rate that initially increase and then decrease. When the temperature increases to a certain value (i.e., Point A in Figures 7 and 8), the resultant tensile force on the aluminum strands reduces to zero and the sag gradually increases. According to equation (26), at point $\mathrm{A}$ the temperature reaches CT. The CT and CC of JNRLH1/G1A-400/65 are $87.5^{\circ} \mathrm{C}$ and $816.2 \mathrm{~A}$, respectively, and those of JNRLH1/G1A-630/55 are $105.4^{\circ} \mathrm{C}$ 
and $142.06 \mathrm{~A}$, respectively. Therefore, the slope of the sagtemperature curves of the conductors near the critical temperature is in the transition phase, i.e., the slope of the sag-temperature curves increases below and decreases above the critical temperature, but does not change greatly near the critical temperature. When the conductor temperature is close to the critical temperature, the steel core in the conductor starts to bear all the loads. However, around CT, the sag reaches a relatively large value, in which the axial force along the conductor becomes relatively lower and the rate of sag increase becomes smaller.

5.4. Temperature-Tension Force Characteristics. The experimental and numerical temperature-tensile force characteristics of heat-resistant aluminum alloy conductor JNRLH1/ G1A-400/65 (with initial tension of $34 \mathrm{kN}$ ) and JNRLH1/ G1A-630/55 (with initial tension of $42 \mathrm{kN}$ ) are compared in Figures 9 and 10. The experiment is performed using the same process in Section 5.3.

Figures 9 and 10 show that the numerical and experimental results fit well (the maximum difference is $5.19 \%$ and $5.63 \%$, respectively). The tensile force of the overhead conductors decreases gradually with the increase of temperature. The $\mathrm{CT}$ and $\mathrm{CC}$ are, respectively, $\left(83.56^{\circ} \mathrm{C}\right.$, $827.64 \mathrm{~A})$ and $\left(100.96^{\circ} \mathrm{C}, 1391.86 \mathrm{~A}\right)$ for the two examples. Below the CT, the tensile force rapidly decreases as the temperature increases and gradually decreases until the critical temperature. It should be noted that the critical point cannot be directly observed according to the curve of temperature vs. tensile force but needs be calculated.

\section{Study of Critical Temperature and Critical Current}

6.1. Layered Stress and Sag at the Critical Point. In this section, the experiment in Section 5.4 is simulated, and the relationship between the current and the layered stress (and sag) at the midpoint of overhead conductors is studied. At CT (or CC), the characteristics of the layered stress and sag are discussed. Figures 11 and 12 show the law of the current with the layered stress on the cross section at the midpoint of JNRLH1/G1A-400/65 and JNRLH1/G1A-630/55, respectively. The legend layer 1 2 (in Figures 11 and 12) represent the internal and external layer of steel core, respectively, the legend layer 3 4 (in Figure 11) and layer 3 5 (in Figure 12) indicate the internal and external layers of aluminum strands, respectively. Figures 13 and 14 show relationships between their sags at the midpoint and the current, respectively. The "A" point in Figures 11-14 indicates the critical current.

Figures 11 and 12 show that the stresses of the steel core of the internal layers are basically the same and the stresses of the aluminum strands of the external layers are basically the same too. With the increase of current, the stresses of the external aluminum strands gradually decrease and those of the external steel core decrease first and then increase. When the current is greater than the critical current, the stresses of the steel core increase rapidly. In Figure 11, the stress of the

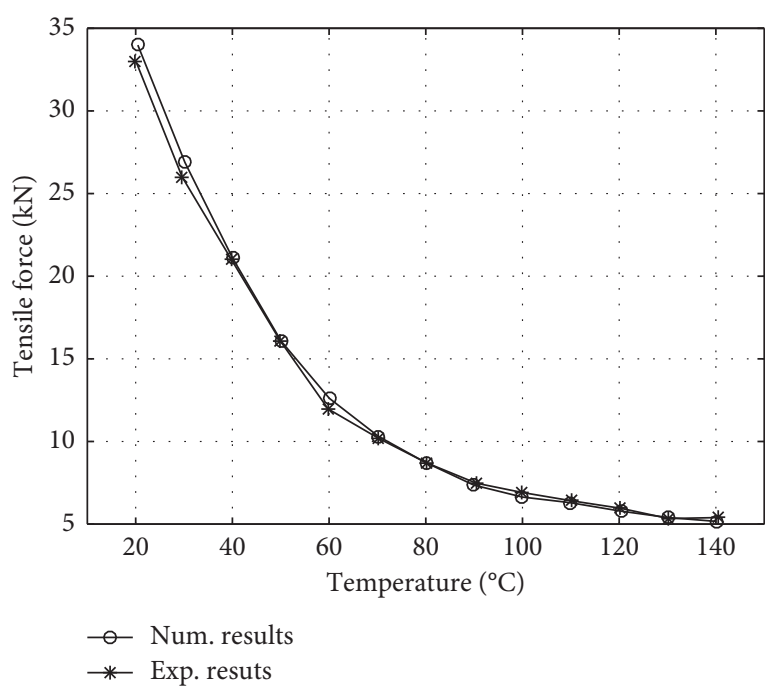

Figure 9: The temperature and tensile force characteristics of conductor JNRLH1/G1A-400/65.

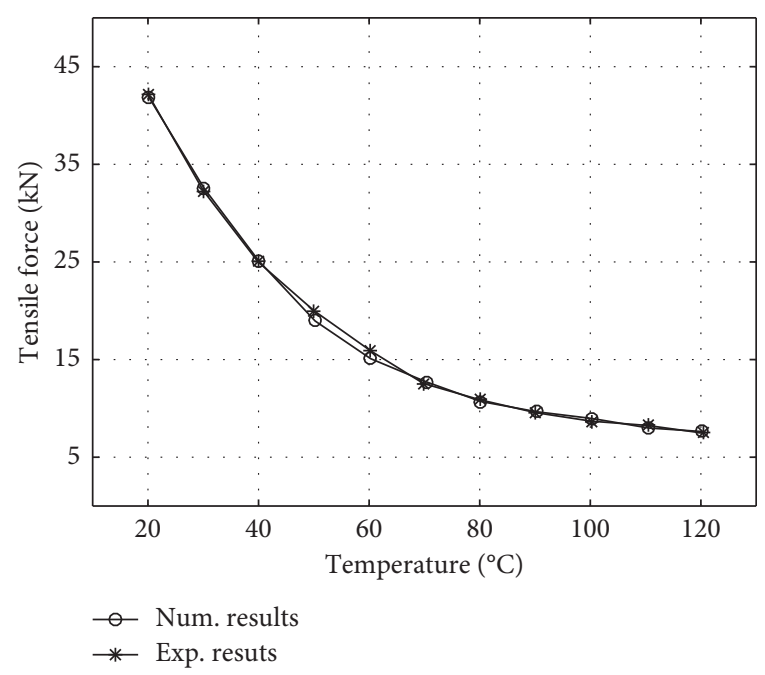

FIgURE 10: The temperature and tensile force characteristics of conductor JNRLH1/G1A-630/55.

internal steel core at critical current is less than the initial stress (no current). However, its stress is far greater than the initial stress in Figure 12. It is shown (in Figures 13 and 14) that the sag (at the midpoint) gradually increases with the increase of current and that, under the critical current, they are 3.8 and 4.7 times more than the initial sag, respectively. This is because when the current is far below the CC, with the increase of current (the temperature rises), the length and sag gradually increase and the tensile force on it decreases leading to gradual reduction in the stress of the internal steel core. When the current (or temperature) is higher than the CC (or CT), the strands (such as aluminum strands) with a larger thermal expansion coefficient will be under pressure rather than tension. The strands (steel core) with a smaller thermal expansion coefficient will resist the tensile force caused by the aluminum strands under pressure but not that of external load, which leads to a rapid increase in the stress 


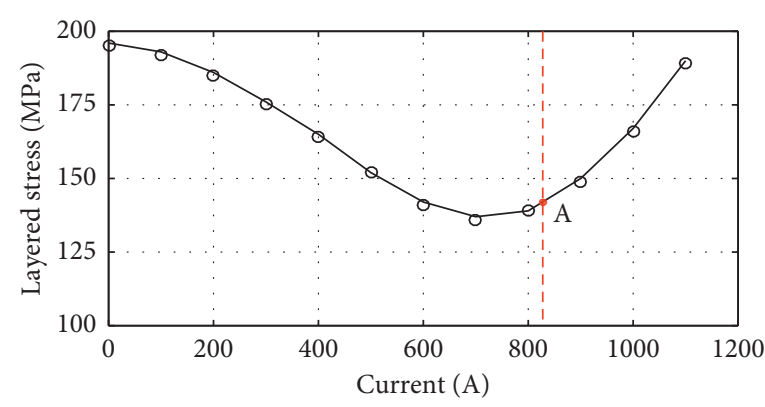

$\begin{array}{ll}- & \text { Layer } 1 \\ \circ & \text { Layer } 2\end{array}$

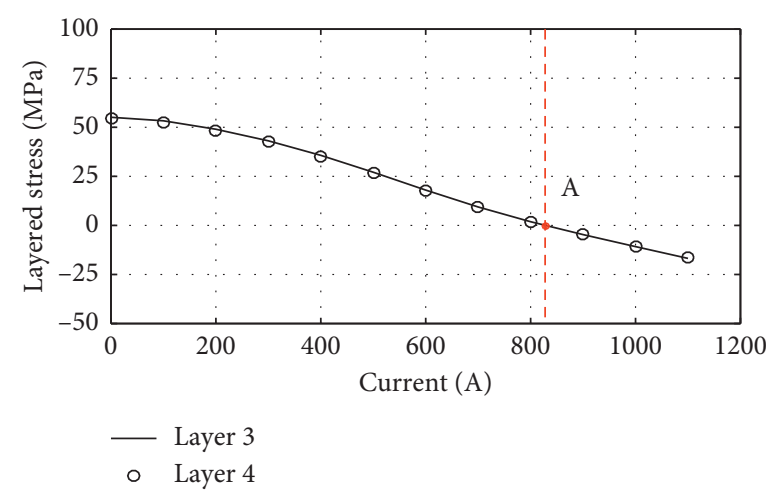

(b)

Figure 11: Relationship between layered stress of conductor JNRLH1/G1A-400/65 and the current: (a) stress of steel core at each layer and (b) stress of aluminum strand at each layer.

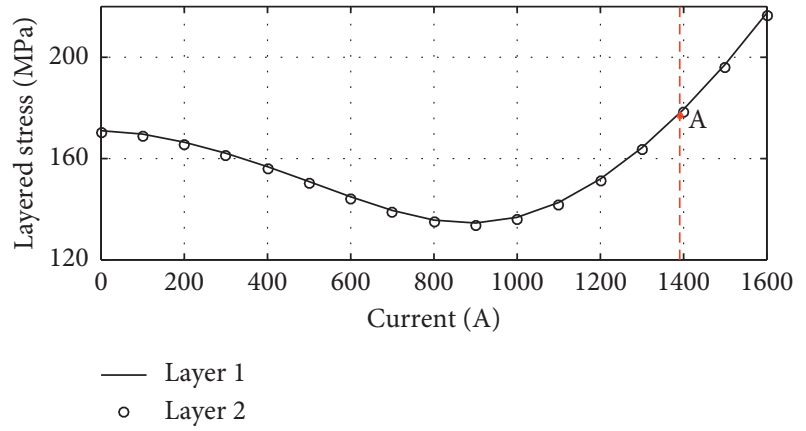

(a)

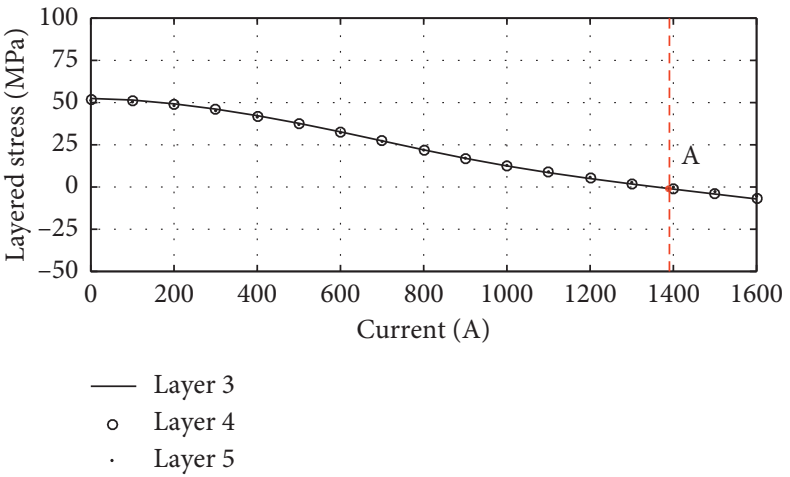

(b)

FIGURE 12: Relationship between layered stress of conductor JNRLH1/G1A-630/55 and current: (a) stress of steel core at each layer and (b) stress of aluminum strand at each layer.

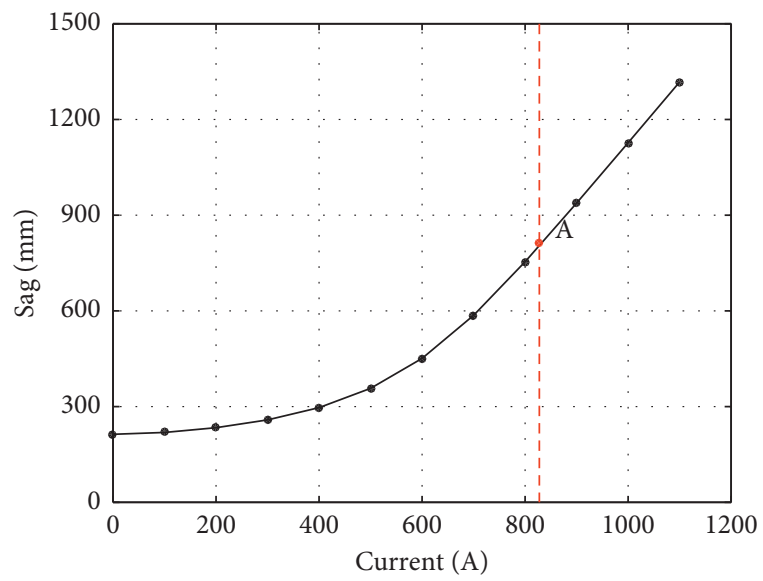

FIGURE 13: Relationship between the sag at the midpoint of conductor JNRLH1/G1A-400/65 and the current.

of the steel core and linear increase in the sag. It is obvious that this stress state is not conducive to the synergy of each layer of strands. In actual operation, the current (or temperature) of the conductor should be controlled to be lower than the critical current (temperature) as much as possible.

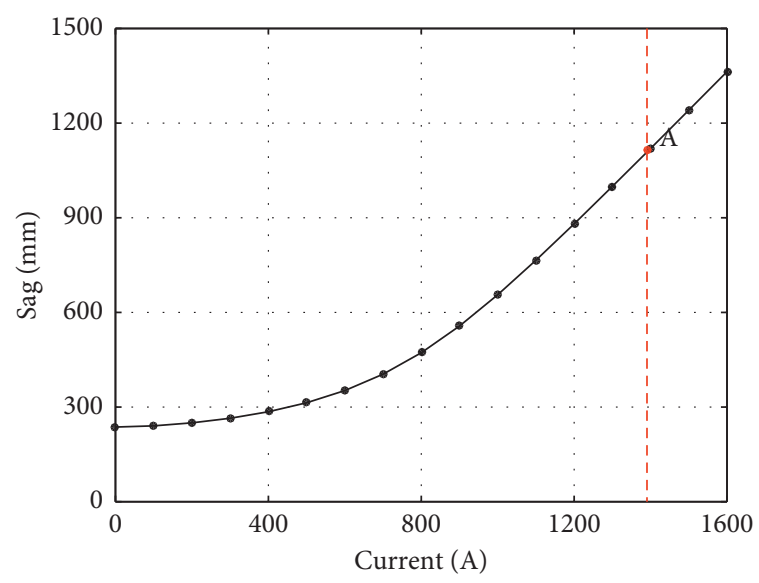

FIgURE 14: Relationship between the sag at the midpoint of conductor JNRLH1/G1A-630/55 and the current.

6.2. The Sensitive Factors of Critical Temperature and Current. As discussed in Section 5.1, the operational current and temperature should be less than the critical values. As the critical temperature and current are related to layered stress and temperature field of conductors, the following factors 


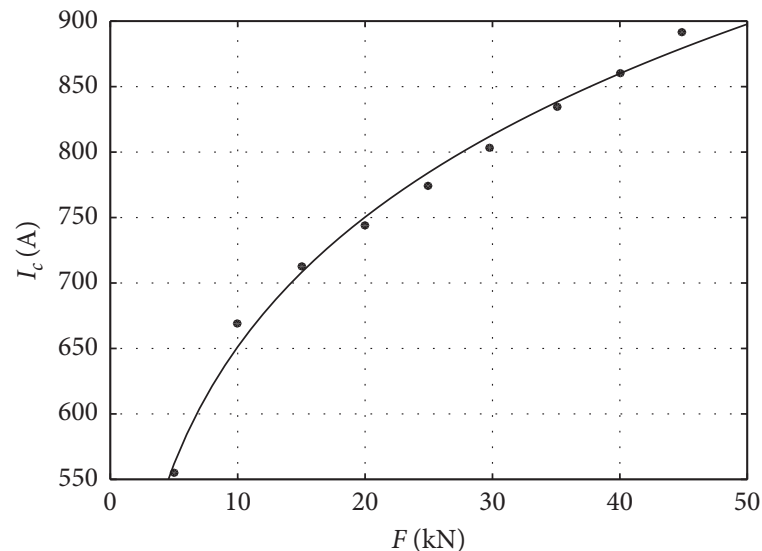

- $I_{c}$ vs. $F$

— Fitted curve

(a)

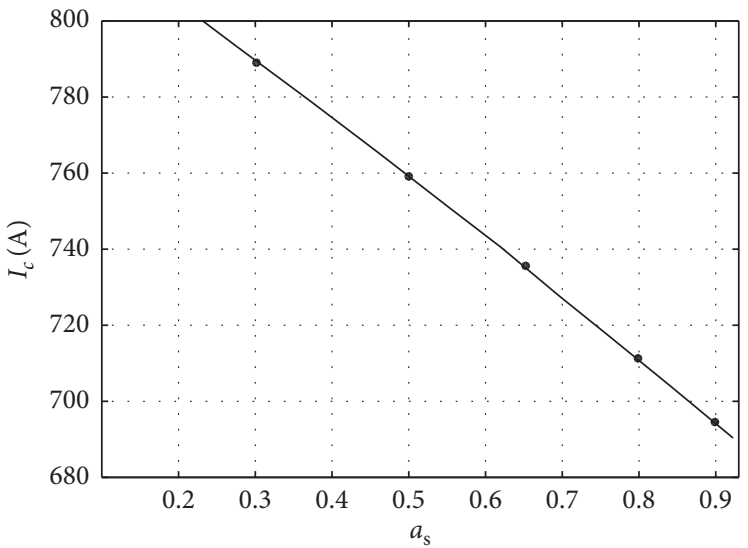

- $I_{c}$ vs. $a_{\mathrm{s}}$

- Fitted curve

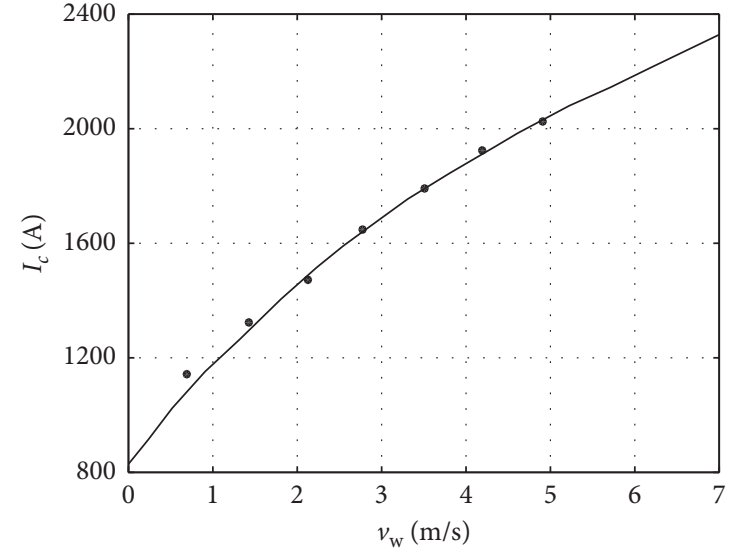

- $I_{c}$ vs. $v_{\mathrm{w}}$

— Fitted curve

(b)

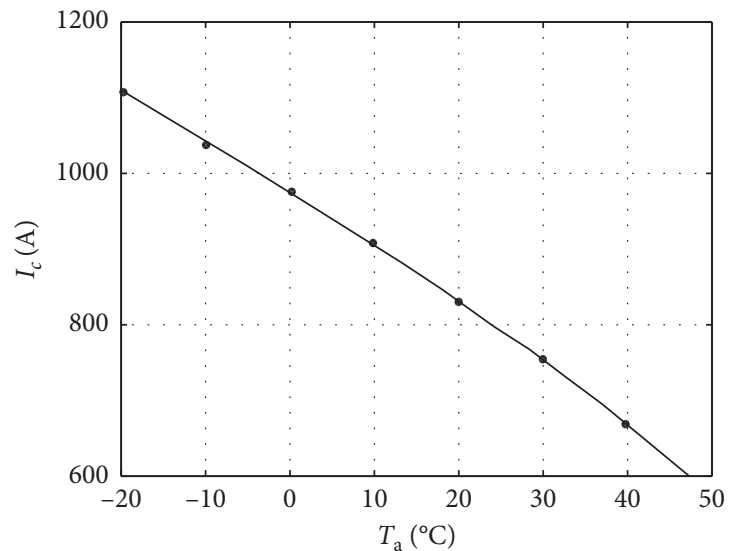

- $I_{c}$ vs. $T_{\mathrm{a}}$

— Fitted curve

(c)

(d)

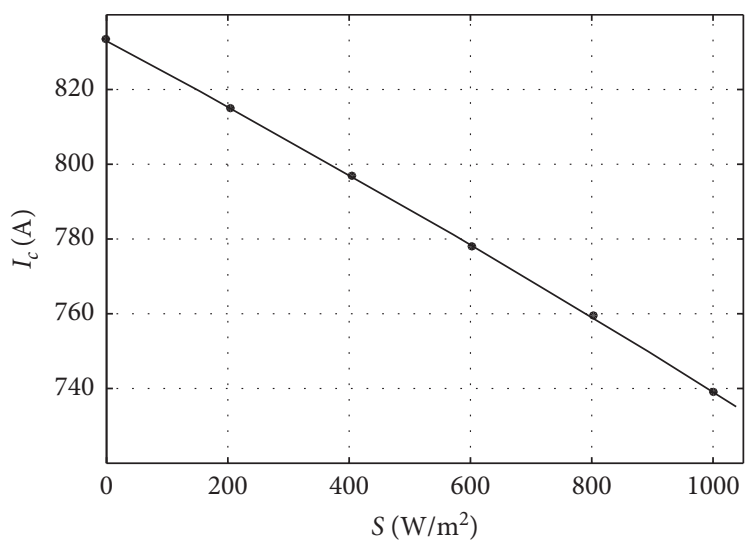

- $I_{c}$ vs. $S$

_ Fitted curve

(e)

FIGURE 15: Relationship between critical current and its factors. (a) Relationship between critical current and horizontal tensile force. (b) Relationship between critical current and wind speed. (c) Relationship between critical current and solar absorption. (d) Relationship between critical current and ambient temperature. (e) Relationship between critical current and solar intensity. 
TABLE 2: The values of the fitting coefficient $a_{i},(i=1 \sim 11)$.

\begin{tabular}{lccr}
\hline Coefficients & Value & & Confidence bounds \\
\hline$a_{1}$ & 203.4001 & -671.671 & 1078.472 \\
$a_{2}$ & 0.300959 & -0.38589 & 0.98781 \\
$a_{3}$ & 7833.395 & -86675.7 & 102342.5 \\
$a_{4}$ & 0.091287 & -0.50256 & 0.685134 \\
$a_{5}$ & 0.998746 & -2.53519 & 4.532683 \\
$a_{6}$ & -39.569 & -110.065 & 30.92676 \\
$a_{7}$ & 2386.236 & -44062.9 & 48835.41 \\
$a_{8}$ & -0.00761 & -0.09472 & 0.079501 \\
$a_{9}$ & 1.132626 & -2.66625 & 4.931498 \\
$a_{10}$ & -0.10697 & -0.14894 & -0.065 \\
$a_{11}$ & -8308.29 & -107465 & 90848.25 \\
\hline
\end{tabular}

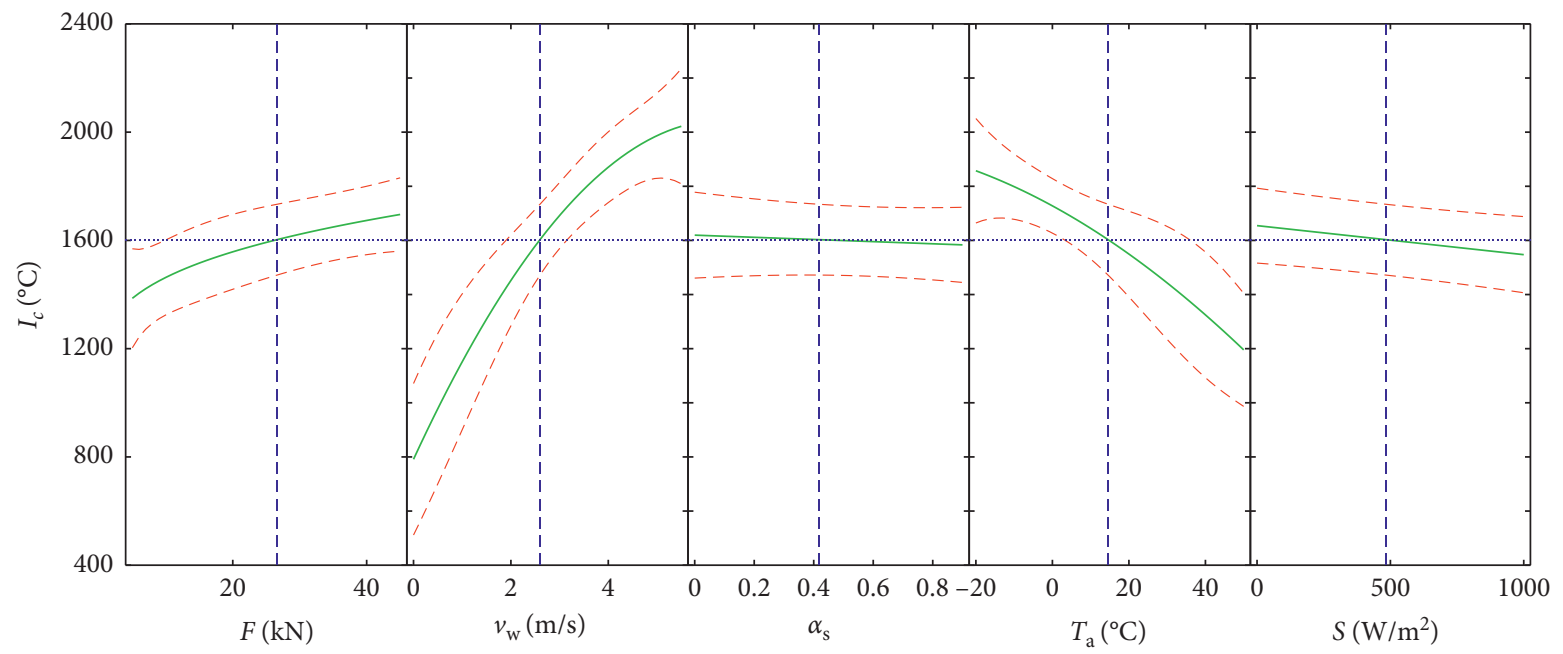

Figure 16: Fitting of critical current and its sensitive factors.

are assumed to be sensitive: (1) solar intensity $S$ with a unit of $\mathrm{W} / \mathrm{m}^{2}$ and range of $0 \sim 1000$; (2) solar absorption $\alpha_{s}$, dimensionless, with a range of $0.23 \sim 0.9$, reflecting the age of the conductors; new bright conductors have an absorption rate of 0.23 and old gray conductors have an absorption rate of 0.9 , and conductors in service period have an absorption rate between them; (3) ambient temperature $T_{a}$ with a unit of ${ }^{\circ} \mathrm{C}$ and range of $-20 \sim 50$; (4) wind speed $v_{\mathrm{w}}$ with a unit of $\mathrm{m} / \mathrm{s}$ and range of $0 \sim 7$; (5) initial tensile force $F$ with a unit of $\mathrm{kN}$ and range of $0 \sim 0.3 F_{\max }$, where $F_{\max }$ indicates the ultimate bearing capacity. In other words, critical temperature and critical current have a functional relation with these variables $T_{c}\left(\alpha_{s}, T_{a}, v_{w}, F, S\right)$ and $I_{c}\left(\alpha_{s}, T_{a}, v_{w}, F, S\right)$.

This section takes the heat-resistant aluminum alloy conductor JNRLH1/G1A-400/65 as an example. First, the fitting of the functional relationships (e.g., linear/quadratic/ exponential functions/trigonometric functions) between critical current and the abovementioned five variables is conducted. The relationships between critical current and each of the five factors are, respectively, shown in Figures 15(a)-15(e). Then, the relationship between critical current and its five factors can be postulated as equation (29) according to the fittings of the individual factor. The fitting coefficients $a_{i},(i=1 \sim 11)$ with a confidence level of $95 \%$ can be obtained with the multifactor method (see Table 2 for specific data). The relationship between critical current and its influencing factors is shown in Figure 16. The two dotted lines in the figure represent the confidence interval of predicted values (with a corresponding confidence level of 95\%):

$$
I=a_{1} F^{a_{2}}+a_{3} \sin \left(a_{4} v_{w}+a_{5}\right)+a_{6} \alpha_{s}+a_{7} \sin \left(a_{8} T_{a}+a_{9}\right)+a_{10} S+a_{11} .
$$

In the same way, the change law of critical temperature with each influencing factor can be obtained (as shown in Figure 17). The results show that the critical temperature has a great correlation with the initial tensile force and little correlation with other factors (i.e., they can be ignored). For function relationship fitting, the following equation can be obtained:

$$
T_{c}=a F^{b}+c,
$$

where $a=13.54, b=0.4206$, and $c=24.72$.

Figures 15 and 16 show that (1) the sensitive factors of critical current are successively wind speed, ambient temperature, horizontal tensile force, solar intensity, and solar absorption according to their significance level. (2) Horizontal tensile force and wind speed are positively correlated with critical current. Solar absorption, solar intensity, and 


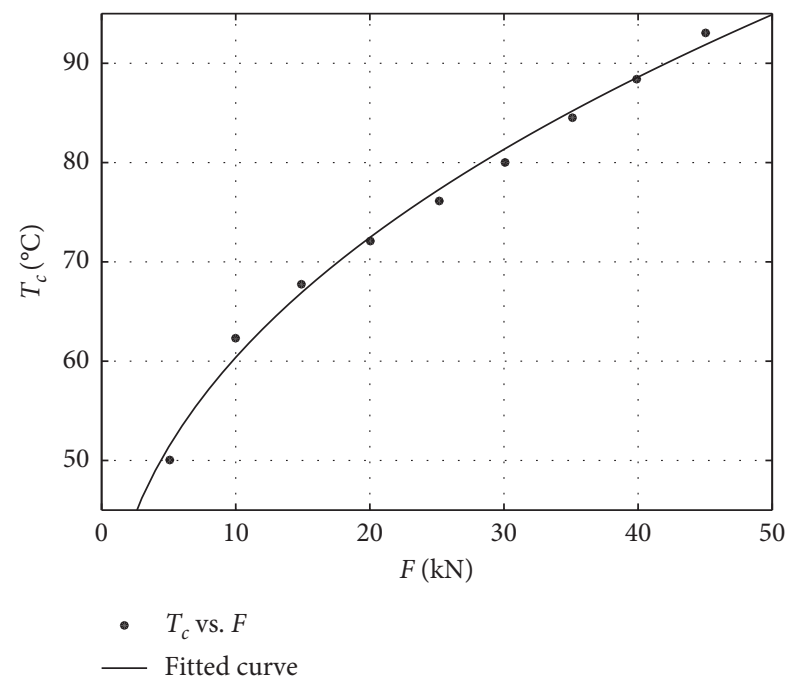

FIGURE 17: Relationship between critical temperature and factors.

ambient temperature are negatively correlated with it. Figure 17 shows that the critical temperature is positively correlated with horizontal tensile force and has little correlation with other factors.

\section{Conclusion}

This article proposes a set of numerical methods for calculating the temperature field, layered stress, and sag of overhead conductors, based on which the critical temperature and critical current are studied. The calculation methods and procedures are verified through experimental results. The authors also studied the relationship between the five most sensitive factors and the critical temperature (or current). The following conclusions are made:

(1) The results of numerical calculation and experiments for conductor temperature agree well. The temperature gradient on the cross section is relatively small; therefore, its impact on the layered stress can be ignored in the calculation. Meanwhile, the average temperature of cross sections rises with the increase of current and drops with the increase of wind speed.

(2) The numerical simulation and experimental results for layered stress in the elastic phase (with strain of less than $0.2 \%$ ) agree each other with acceptable accuracy. The tensile stresses of the internal aluminum strands are slightly greater than those of the external ones.

(3) The calculated sages fit well with the experimental results. With the increase of temperature, the sag increases with a rate that first increases and then decreases, that is, when the conductor temperature increases close to the critical temperature, the sag of the conductors gradually increases. The calculated tensile forces agree well with experimental ones. Below the critical temperature, the tensile force decreases rapidly with the increase of temperature, while the changing rate decreases close to the critical temperature. The critical temperature cannot be directly observed according to the curve of temperature vs. tensile force before calculation.

(4) With the increase of current, the stresses of the steel core first decrease and then increase, while those of the aluminum monotonically decrease. When the current (or temperature) of overhead conductors is higher than the critical current (or temperature), the stresses of the steel core rapidly increase and the sag linearly increases with increasing temperature. At the critical current, the sag increases to 3-4 times of its original value. In some cases, the stresses of steel cores in the conductor are far greater than their initial value. In actual operation, the current (or temperature) of conductors should be controlled so that it remains lower than the critical current (or temperature) as much as possible.

(5) The critical temperature is positively correlated with horizontal tensile force and has little correlation with other factors. According to their relative sensitivities, the importance ranking of the influencing factors to critical current are (from high to low): wind speed, ambient temperature, horizontal tensile force, solar intensity, and solar absorption. Horizontal tensile force and wind speed are positively correlated with critical current. Solar absorption, solar intensity, and ambient temperature are negatively correlated.

\section{Data Availability}

All the data used to support the findings of this study are included within the article.

\section{Disclosure}

Any opinions, findings, conclusions, or recommendations expressed in this publication are those of the authors and do not necessarily reflect the views of the sponsors.

\section{Conflicts of Interest}

The authors declare that there are no conflicts of interest.

\section{Acknowledgments}

The authors acknowledge the financial support from the National Key Research and Development Program of China (Grant no. 2016YFC0701106) and the National Natural Science Foundation of China (Grant nos. 51578473 and 51978591). The authors also acknowledge the financial support from the Scientific Research Fund of Institute of Engineering Mechanics, China Earthquake Administration (Grant nos. 2019EEEVL0501, 2019B02, and 2019A02).

\section{References}

[1] J. Wei, Z. Wang, X. Feng et al., "Study on the mechanical properties of heat-resistant aluminum alloy conductors," pp. 35-36+47, Water Conservancy \& Electric Power Machinery, Ziyang, China, 2005, in Chinese. 
[2] G. Wang and H. Huang, "Calculation of stress and sag of the energy-saving capacity-expanded conductors (in Chinese)," Electric Wire\&Cable, pp. 11-14, 2009.

[3] K. Yang, Comparison of Stress and Sag Characteristics of Augmented Capacity Conductors, pp. 31-33, Yunnan Electric Power, Kunming, China, 2013, in Chinese.

[4] R. Bush, W. Black, and T. Champion, "Experimental verification of a real-time program for the determination of temperature and sag of overhead lines," IEEE Transactions on Power Apparatus and Systems, vol. PAS-102, no. 7, pp. 2284-2288, 1983.

[5] G. Clark, "Summary report on the effects of high operating temperatures on conductors and hardware behavior," Report, Ontario Hydro Research Division, Toronto, Canada, 1977.

[6] D. A. Douglass, "Radial and axial temperate gradients in bare stranded condctor," IEEE Transactions on Power Delivery, vol. 1, no. 2, pp. 7-15, 1986.

[7] D. Douglass, L. Kirkpatrick, and L. Rathbun, "AC resistance of ACSR-Magnetic and temperature effects," IEEE Transactions on Power Apparatus and Systems, vol. PAS-104, no. 6, pp. 1578-1584, 1985.

[8] S. D. Foss, S. H. Lin, and R. Carberry, "Significance of the conductor radial temperature gradient within a dynamic line rating methodology," IEEE Transactions on Power Delivery, vol. 2, no. 2, pp. 502-511, 1987.

[9] J. F. Hall, A. K. Deb, and J. Savoullis, "Wind tunnel studies of transmission line conductor temperatures," IEEE Transactions on Power Delivery, vol. 3, no. 2, pp. 801-812, 1988.

[10] V. T. Morgan, "Rating of bare overhead conductors for continuous currents," Proceedings of the Institution of Electrical Engineers, vol. 114, no. 10, pp. 1473-1482, 1967.

[11] V. T. Morgan, "Rating of bare overhead conductors for intermittent and cyclic currents," Proceedings of the Institution of Electrical Engineers, vol. 116, no. 8, pp. 1361-1376, 1969.

[12] V. Morgan, "A theoretical and experimental analysis of the factors which determine the thermal behaviour of an exposed cylindrical current-carrying conductor," Ph. D. thesis, University. London, London, UK, 1971.

[13] IEEE, IEEE Standard for Calculating the Current-Temperature Relationship of Bare Overhead Conductors IEEE Std 738-2012 (Revision of IEEE Std 738-2006-Incorporates IEEE Std 7382012 Cor 1-2013), pp. 1-72, IEEE, Piscataway, NJ, USA, 2013.

[14] Z. He, Z. Li, and P. Liang, "ANSYS calculation method of temperature and current-carrying capacity for transmission lines," Zhejiang Electric Power, vol. 29, pp. 1-5, 2010, in Chinese.

[15] C. Zhao, L. Zheng, C. Tian et al., "Numerical study on temperature field of $66 \mathrm{kV}$ overhead transmission line," Power System Technology, pp. 34-36, 2007, in Chinese.

[16] M. Zunec, I. Ticar, and F. Jakl, "Determination of current and temperature distribution in overhead conductors by using electromagnetic-field analysis tools," IEEE Transactions on Power Delivery, vol. 21, no. 3, pp. 1524-1529, 2006.

[17] R. Stephen, D. Douglas, G. Mirosevic et al., Thermal Behaviour of Overhead Conductors, Cigré, Paris, France, 2002.

[18] T. Shao, Calculation of Electrical Engineering of Overhead Transmission Line, China Electric Power Press, Beijing, China, 2003, in Chinese.

[19] S. Byrd, H. Ni, and X. Rui, "Application of the layer characteristics to the intensity of overhead conductors (in Chinese)," Southern Power System Technology, vol. 3, pp. 49-51, 2009.

[20] L. Zheng and Z. Sun, "Stress analysis of aluminium stranded wire and steel-cored aluminium stranded wire," Journal of
Wuhan Uniersity of Hydraulic and Electric Engineering, pp. 66-69, 1997, in Chinese.

[21] K. Xiao, Y. Liu, P. Li et al., Numerical Analysis on Temperature and Stress Filed Coupling of Overhead Conductors, pp. 97-102, Guangdong Electric Power, Guangzhou, China, 2015, in Chinese.

[22] D. Loudon, D. A. Douglass, R. G. Stephen, and G. C. Sibilant, "Calculation accuracy of high-temperature sag for ACSR in existing lines," Cigre Science \& Engineering, vol. 7, 2017.

[23] O. Nigol and J. S. Barrett, "Characteristics of ACSR conductors at high temperatures and stresses," IEEE Transactions on Power Apparatus and Systems, vol. PAS-100, no. 2, pp. 485-493, 1981.

[24] C. B. Rawlins, "Some effects of mill practice on the stress strain behavior of ACSR," IEEE Transactions on Power Delivery, vol. 14, no. 2, pp. 602-629, 1999.

[25] Standardization Administration of China, GB/T 1179-2008. Round Wire Concentric Lay Overhead Electrical Stranded Conductors. China, Standardization Administration of China, Beijing, China, 2008.

[26] X. Peng and Y. Lin, Experimental Investigation on Impact of Ambient Wind Velocity on Ampacity of Overhead Transmission Lines and Temperature Rise, pp. 20-25, Guangdong Electric Power, Guangzhou, China, 2012, in Chinese. 